\title{
Challenges faced by nurses in india-the major workforce of the healthcare system
}

\begin{abstract}
Nursing binds human society with a bond of care and affection. Nursing is a calling to care, which offers an oasis of poignant stories and pool of challenges. Despite of urbanization and globalization in India, the healthcare system in the country continues to face formidable changes. Nurses play an integral role in the healthcare industry, providing care to the patients and carrying out leadership roles in hospitals, health systems and other organizations. It is of paramount importance that all people everywhere should have access to a skilled, motivated and supportive nursing care within a robust healthcare system. The importance of nurses in healthcare should be underlined for attempting to create a better task force for better quality care for all. There are certain challenges which the Nurses in the present healthcare system face. These challenges arise due to issues at the organizational, state and national level. It is of utmost importance to first recognize and understand each and every possible challenge faced by the nurses in order to deal with them efficiently. Not just recognize and understand them but also find solutions to mitigate them.
\end{abstract}

Keywords: challenges, nurses and Healthcare system
Volume 2 Issue 4 - 2017

\author{
Manju Chhugani, Merlin Mary James \\ Department of Nursing, Rufaida College of Nursing, India
}

Correspondence: Merlin Mary James, Tutor, Rufaida College of Nursing, India, Tel +9l-997/882433,

Email merlinjames1988@yahoo.com

Received: February 22, 2017 | Published: April 05, 2017

\section{Mini Review}

Nursing binds human society with a bond of care and affection Nursing is a calling to care, which offers an oasis of poignant stories and pool of challenges. The scope of nursing practice has expanded and extended to different settings other than hospital only. Nurses deal with the most precious thing in this wide world-the human life.

Nurses are often the linchpin component across a wide continuum of care. A nurse's professional skills and training contribute significantly to successful patient outcomes in a variety of care settings--from acute and tertiary care to prevention and wellness programs. ${ }^{2}$ Their smiling face and compassionate touch and care provides great satisfaction to the patient.

Despite of urbanization and globalization in India, the healthcare system in the country continues to face formidable changes. The healthcare system has become increasingly detached from the curative aspect and more focusing on the satisfaction of material needs and enlarging the profit-earning aspects. This has led to unaffordability of the curative care to many common people due to the present framework of the healthcare system in the country. Subsequently the healthcare system is being plagued with various problems. The solution is to delve deeper into the roots of the problems and explore possible solutions to curb them.

Nurses play an integral role in the healthcare industry, providing care to the patients and carrying out leadership roles in hospitals, health systems and other organizations. Although nursing profession can be very rewarding but it is equally challenging and it entails a huge level of dedication and commitment. Nurses needs to be focused on not only the patient needs but also on the management of system of care. This often creates unfortunate hassles irrespective of how hard the nurse's works towards patient care. They are coordinators and custodians of patient care. This entails lot of managerial skills where they need to possess apart from technical skills
Reduced workforce and lack of quality care leads to overburdened workforce which further leads to higher morbidity and mortality. It is of paramount importance that all people everywhere should have access to a skilled, motivated and supportive nursing care within a robust healthcare system. The importance of nurses in healthcare should be underlined for attempting to create a better task force for better quality care for all.

However, there are certain challenges which the Nurses in the present healthcare system face. These challenges arise due to issues at the organizational, state and national level. It is of utmost importance to first recognize and understand each and every possible challenges faced by the nurses in order to deal with them efficiently. Not just recognize and understand them but also find solutions to mitigate them.

In India, the healthcare system is undergoing a radical change and there are unmet health targets. The change is due to the change in demographics, advancement in medical technology, profit earning mentality, immigration, task shifting, education-service gap and economic recession to list a few. Subservient to medical fraternity even though long back it has been developed as profession (WHO). Nurses facilitate co-operation from other healthcare providers, for e.g., doctors, paramedical staff and other ancillary staff. There are several daunting challenges faced by nurses at workplace which leave them less efficient in rendering quality care to patients, thereby hoisting an unhealthy reputation to that particular healthcare setting. Nevertheless, these challenges are arguably the primary motivators for nurses to leave their profession, less students opting for nursing profession, thereby contributing to staff shortage. They move to other countries as remuneration and working condition and respect better.

\section{Challenges faced by nurses at workplace}

\section{Workplace mental violence}

Workplace violence is widespread in healthcare settings. Huge 
amount of workload and responsibilities on the staff can often lead to disturbed mental peace which will ultimately lead to less efficient care. Multiple tasks can pose a problem in a healthcare unit. Workplace mental violence can be also in the form of threats, verbal abuse, hostility and harassment, which can cause psychological trauma and stress. At times verbal assault can escalate to physical violence. In a healthcare setting, the possible sources of violence include patients, visitors, intruders and even co-workers. From 2002 to 2013, incidents of serious workplace violence (those requiring days off for the injured worker to recuperate) were four times more common in healthcare than in private industry on average. Patients are the largest source of violence in healthcare settings, but they are not the only source. In 2013, 80 percent of serious violent incidents reported in healthcare settings were caused by interactions with patients. Other incidents were caused by visitors, co-workers, or other people. At many instances workplace violence is under-reported. ${ }^{3}$

\section{Shortage of staff}

Deficient Manpower leads to unmanageable patient load and disparity in the Nurse: Patient ratio. Nurse: Patient ratio needs to be well maintained as it highly affects the patient care delivery system. When nurses are forced to work with high nurse-to-patient ratios, patients die, get infections, get injured, or get sent home too soon without adequate education about how to take care of their illness or injury. So they return right back to the hospital, often sicker than before. When nurses have fewer patients, they can take better care of them. ${ }^{4}$ When there are sufficient number of nurses in a healthcare setting, the nurses have more time to advocate with the patients and their relatives about the plan of patient care and s/he can ensure that the patient gets everything $\mathrm{s} /$ he needs, and thereby patients are more likely to thrive in such situations.

\section{Workplace health hazards}

Nurses confront a high risk of developing occupational health hazards if not taken proper precautions and care. Nurses are confronted with a variety of biological, physical, and chemical hazards during the course of performing their duties. The level of occupational safety and health training and resources available to nurses, and the incorporation, implementation, and use of such training and resources with management support and leadership are critical factors in preventing adverse outcomes from the occupational safety and health hazards nurses are exposed to on a daily basis. ${ }^{2}$

\section{Long working hours}

Short staffing pattern in a health care unit often results in long working hours and double shifts of staff nurses. It is evidently affecting the health of the nurses. It is quite difficult for a nurse to provide efficient nursing care with exhausted state of mind and body.

\section{Lack of synchronicity}

Disharmony and lack of teamwork is an emerging challenge in the heath-care sector. Harmonious relationship amongst healthcare workers is an essential requirement for the healthcare system. Nurses bear the indirect opprobrium of every dreadful incident which occurs in the hospital. If the patient is not satisfied by the care rendered in the hospital, all the blame is accrued to the nurses, even if it is not her fault. Inadequacy in the care rendered may vary from ineffective medical care to non-availability of doctors, and yet nurses are being blamed. Non availability of equipment in hospital, which in turns affects the quality of care. Although the responsibility is not necessarily of nurses, yet nurses are ultimately responsible for patient care environment in their wards.

\section{Lack of recognition}

Hospitals must be safe places for sick folks and their nursing services carry responsibilities that are not always recognized. ${ }^{1}$ There is no support system for nurses and hence their performances are usually not projected well. During inspections conducted in Hospitals by Medical Council of India and Indian Nursing Council, nurses play a vital role in all facilitations, and at the culmination of the inspections, the outcomes are not shared with them and they are not acknowledged for the work performed.

\section{Non-nursing roles}

In almost all healthcare settings, nurses undertake roles which are not of their forte, hence they are left with minimal time to carry out their actual roles and responsibilities. They are spending more time than necessary doing non-nursing-related work, for e.g., billing, record keeping, inventory, laundry, diet, physiotherapy, absconding of patient, etc., thereby diminishing time for patient care. If at any instance, there is any fault in these roles, the nurses have to bear the brunt of that in the form of cancellation of leaves, salary deductions etc., Very little efforts have been made in any jurisdiction to explicitly address this.

\section{Solutions to curb the challenges}

All the listed challenges are somehow interlinked and interdependent. It is necessary for us to look deep within these problems and to reach to the core of these challenges in order to find resolutions for the same.

\section{Positive practice environment}

Work environment: Work environment plays a large role in the ability of providing quality care. It impacts everything from the safety of patients and their caregivers to job satisfaction. There needs to be employer friendly work environment. Safety and security of the nurses should be given importance. To maximize the contributions nurses, make to society, it is necessary to protect the dignity and autonomy of nurses in the workplace. ${ }^{5}$ A Healthy Work Environment is one that is safe, empowering, and satisfying. A culture of safety is paramount, in which all leaders, managers, health care workers, and ancillary staff have a responsibility as part of the patient centered team to perform with a sense of autonomy, professionalism, accountability, transparency, involvement, efficiency, and effectiveness. All must be mindful of the health and safety for both the patient and the health care worker in any setting providing health care, providing a sense of safety, respect, and empowerment to and for all persons. ${ }^{6}$ Harmonious human relations and incentives in work settings may serve as motivation and encouragement for the nurses.

Equipment/materials: The availability and adequacy of samples of equipment and consumable supplies is often a matter of concern. Usually staff report that they are crippled by unavailability and inadequacy of certain equipment and supplies. The problems ranged from the inadequacy of life saving supplies and equipment including IV drugs adrenaline, oxygen and autoclaves to relatively cheap 
supplies including gauze and cotton wool. The hospital management should ensure at regular basis that the supplies and equipment are adequately available for the smooth functioning of the hospital.

\section{Positive team work}

A team needs to be taught about importance of team work and a good team can always conquer the goal of effective and quality patient care. It can also accelerate the focus on curative care of the patients.

\section{Recruitment/retention policy}

A proper and well planned policy for recruitment and retention has to be included in an organization in order to enhance the manpower for better support and care.

\section{Closing education-service gap}

Every heath care organization should be focusing on eradicating the difference between what is taught to the nurses during their study period and what is being done practically by them in hospitals. Practical and theoretical things of nursing aspects should be merged to an extent to close the education - service gap. Nursing colleges, year by year are strengthening their educational programs and their supervision in an effort to develop thoughtful nurses and to safeguard patients whom they tend. Students need to be taught reverence for human life, as tragedy lurks round every corner in a hospital-any hospital, good or bad and that price of safety is eternal vigilance. ${ }^{1}$

\section{Workload balance (quality/quantity)}

Workload often leads to unwanted hassles and loss of mental peace which ultimately leads to less efficient care. An organization should try to balance the workload by distributing it equally among all the health care members so as to get the desired results out of a health care team.

\section{Evidence based practice}

Nurses should also deviate a part of their focus towards evidence based practice. Various practices have related researches which can be read by the nurses to see if that practice is actually effective or not. Regular reading of research articles and studying various experimental studies can improve the knowledge and practice of nurses and thus can have a huge positive effect of patient health care and curative care too Figure 1.

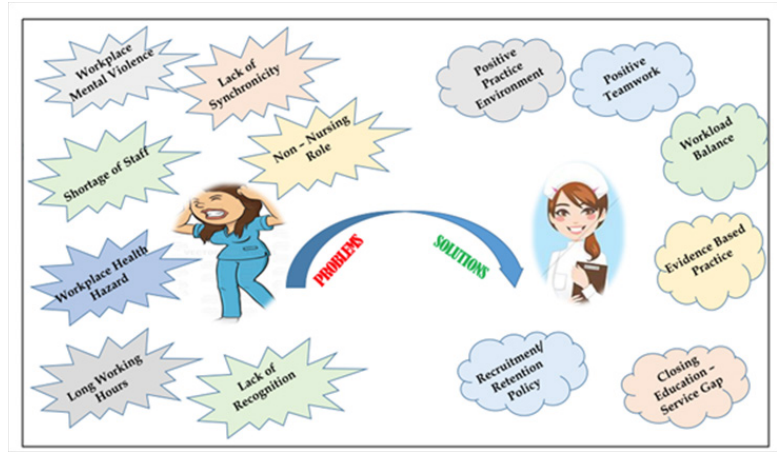

Figure I Nursing problems and solutions.

\section{Conclusion}

Patient and the public have the right to the highest performance from the healthcare professionals and this can only be achieved in a workplace that enables and sustains a motivated and well-prepared workforce. Catering to the needs of nurses and combating their challenges can make nurses empowered, encouraged, challenged and affirmed to continue doing what they do best without any barriers.

\section{Acknowledgements}

None.

\section{Conflict of interest}

The author declares no conflict of interest.

\section{References}

1. Medical chivalry and team work. American Journal of Nursing. 1927;27(5):367.

2. Ramsay, D James. A new look at nursing safety: The development and Use of JHAs in the emergency department. The Journal of Sh \& $e$ Research. 2005;2(2):1-18.

3. https://www.osha.gov/Publications/OSHA3826.pdf

4. http://www.truthaboutnursing.org/faq/short-staffed.html

5. http://www.nursingworld.org/workenvironment

6. http://www.nursingworld.org/MainMenuCategories/WorkplaceSafety/ Healthy-Work-Environment 